ASTHMA

\title{
Steroid naive eosinophilic asthma: anti-inflammatory effects of fluticasone and montelukast
}

\author{
L Jayaram, E Pizzichini, C Lemière, S F P Man, A Cartier, F E Hargreave, M M M Pizzichini
}

Thorax 2005;60:100-105. doi: 10.1136/thx.2004.021634

See end of article for authors' affiliations ......................

Correspondence to: Dr M M M Pizzichini, NUPAIVA, Hospital Universitário da UFSC, Campus Universitário, Florianopolis, Brazil; mpizzich@matrix.com.br

Received 15 January 2004 Accepted 11 October 2004

\begin{abstract}
Background: Inhaled corticosteroids and leukotriene receptor antagonists reduce airway eosinophilia and have been used as first line anti-inflammatory therapy for mild persistent asthma.

Methods: A multicentre, randomised, placebo controlled, parallel group study was performed to compare the anti-inflammatory effects of fluticasone propionate and montelukast as measured by sputum eosinophils in 50 adults with symptomatic steroid naive asthma and sputum eosinophilia of $\geqslant 3.5 \%$.

Results: Eighteen patients received low dose fluticasone $(250 \mu \mathrm{g} /$ day), 19 received montelukast (10 mg/ day), and 13 were given placebo for 8 weeks. Fluticasone treatment resulted in a greater reduction in sputum eosinophils (geometric mean (SD) $11.9(2.3) \%$ to $1.7(5.1) \%$ ) than montelukast (10.7 (2.3)\% to 6.9 (3.8)\%; $p=0.04$ ) or placebo (15.4 (2.4)\% to $7.8(4.2) \% ; p=0.002)$, and improvement in $\mathrm{FEV}_{1}$ (mean (SD) $2.6(0.9)$ I to 3.0 (0.9) I) than montelukast $(2.8(0.7)$ I to $2.8(0.9) \mathrm{I} ; \mathrm{p}=0.02)$ or placebo $(2.4$ (0.8) I to 2.4 $(0.9) \mathrm{l} ; \mathrm{p}=0.01)$. Treatment with fluticasone suppressed sputum eosinophilia within a week while montelukast only attenuated it. The effect of montelukast was maximal at 1 week and was maintained over 4 weeks. The effect of fluticasone was maintained over 8 weeks while that of montelukast was not.

Conclusions: Montelukast is not as effective as low dose fluticasone in reducing or maintaining an antiinflammatory effect in steroid naïve eosinophilic asthma.
\end{abstract}

A nti-inflammatory treatment is critical in the management of asthma ${ }^{12}$ because airway inflammation is regarded as the primary cause of asthma symptoms, exacerbations, reversible airflow limitation, airway hyperresponsiveness (AHR), and remodelling. The latter is thought to contribute to the AHR and development of chronic airflow limitation. ${ }^{3}$ Airway inflammation can be easily measured in induced sputum cell counts. Normal values are well documented $^{5}$ and the measurements are reliable, valid, and responsive. ${ }^{6}$

Sputum cell counts demonstrate different types of inflammation due to different causes. These are eosinophilic (due to inhaled allergens or chemical sensitisers to which the patient is allergic or sensitised, or to inadequate steroid treatment), neutrophilic (which can be trivial and non-specific or more intense due to viral or bacterial infections), eosinophilic and neutrophilic, or neither. ${ }^{7}$ Differentiating these types is important for refining treatment. For example, eosinophilia responds to adequate steroid treatment while current evidence suggests that, if there is no eosinophilia, steroid treatment is ineffective. ${ }^{8}$

Inhaled corticosteroids such as fluticasone propionate are the gold standard anti-eosinophilic inflammatory therapy. ${ }^{12}$ They reduce symptoms, ${ }^{9}$ airflow limitation, ${ }^{10}{ }^{11}$ AHR $^{12}{ }^{13}$ exacerbations, ${ }^{14}$ hospital admissions, ${ }^{15} 16$ and mortality ${ }^{15-17}$ due to asthma. Leukotriene receptor antagonists such as montelukast also have anti-inflammatory properties, reducing $^{18}{ }^{19}$ or preventing ${ }^{20}$ airway eosinophilia in asthma. When compared with placebo they also improve asthma symptoms, ${ }^{21}$ airway function, ${ }^{22}$ and reduce asthma exacerbations. ${ }^{23}{ }^{24}$ As a result, leukotriene antagonists have been acknowledged by some guidelines ${ }^{2}$ as acceptable first line anti-inflammatory treatment.

However, there is limited direct evidence to support the use of the leukotriene antagonists as first line anti-eosinophilic inflammatory treatment in comparison with an inhaled steroid. Two large randomised controlled trials compared the clinical efficacy of montelukast ${ }^{25}$ or zafirlukast ${ }^{26}$ with fluticasone propionate. They showed that the benefit from treatment with the leukotriene receptor antagonists was limited compared with low doses of fluticasone. One crossover study, ${ }^{27}$ not placebo controlled, compared the effects of inhaled fluticasone $200 \mu \mathrm{g} /$ day with montelukast $10 \mathrm{mg} /$ day on inflammatory markers in induced sputum. Fluticasone was shown to decrease sputum eosinophils significantly after 4 weeks. Montelukast also decreased eosinophils after 4 weeks, but not significantly. Although the authors claimed fluticasone treatment to be superior, the difference between the interventions was not significant.

The primary objective of this study was therefore to compare the magnitude of anti-inflammatory effects of montelukast with fluticasone in subjects with asthma and sputum eosinophilia in a four centre, randomised, double blind, placebo controlled trial over 8 weeks. The antiinflammatory effects were measured by induced sputum eosinophils.

\section{METHODS}

\section{Participants}

Adults with persistent symptomatic asthma who had only taken a short acting bronchodilator for at least 2 months were recruited from the chest clinics of three Canadian and one Brazilian research centre (table 1). Asthma was diagnosed by standard criteria $^{2}$ or by AHR to methacholine with a $\mathrm{PC}_{20}$ of $<8 \mathrm{mg} / \mathrm{ml}$ if the $\mathrm{FEV}_{\mathrm{l}} / \mathrm{SVC}$ was $>70 \%$ (fluticasone $\mathrm{n}=4$, montelukast $\mathrm{n}=1$, placebo $\mathrm{n}=2$ ). All subjects had induced sputum eosinophilia of $\geqslant 3.5 \%$ (normal $<2 \%) .{ }^{5}$ None had symptoms of a cold or flu during the month before the start of the study.

The research ethics boards of the participating centres approved the study and each participant gave written informed consent.

\section{Design of study}

This was a four centre randomised, double blind, double dummy, parallel group placebo and active controlled trial 
Table 1 Characteristics of patients at baseline

\begin{tabular}{|c|c|c|c|c|}
\hline & $\begin{array}{l}\text { Placebo } \\
(n=12)\end{array}$ & $\begin{array}{l}\text { Fluticasone } \\
(n=18)\end{array}$ & $\begin{array}{l}\text { Montelukast } \\
(\mathrm{n}=19)\end{array}$ & $p$ value \\
\hline Age (years) & $38.8(12.2)$ & $35.4(13.9)$ & $31.4(9.9)$ & 0.3 \\
\hline Sex (no male) & 4 & 8 & 8 & 0.8 \\
\hline Smoking (current/ex) & $2 / 0$ & $0 / 5$ & $3 / 2$ & 0.6 \\
\hline Atopic (n) & 10 & 16 & 16 & 0.9 \\
\hline Symptoms score* & $22.5(4.5)$ & $23.2(6.4)$ & $25.6(5.5)$ & 0.3 \\
\hline Salbutamol (puffs/day) & $2.6(1.9)$ & $3.3(2.6)$ & $3.3(3.1)$ & 0.8 \\
\hline Pre BD FEV 1 (\% pred) & $80.3(22.5)$ & $72.0(16.0)$ & 76.7 (15.9) & 0.4 \\
\hline Pre BD FEV 1 /SVC (\%) & 67.1 (15.2) & 67.1 (12.2) & $67.9(9.2)$ & 1.0 \\
\hline Change in $\mathrm{FEV}_{1}$ after $\mathrm{BD}(\%)$ & $20.2(15.9)$ & $18.1(15.6)$ & $18.5(9.6)$ & 0.9 \\
\hline Sputum eosinophils $(\%)^{\star *}$ & $15.4(2.4)$ & $11.9(2.3)$ & $10.7(2.3)$ & 0.1 \\
\hline \multicolumn{5}{|c|}{$\begin{array}{l}\text { Data are expressed as mean (SD). } \\
\text { BD, bronchodilator; } \mathrm{FEV}_{1} \text {, forced expiratory volume in } 1 \text { second; SVC, vital capacity } \\
\text { Atopic means one or more positive allergy skin prick test, } \mathrm{n} \text { indicates the number of atopic subjects. } \\
{ }^{*} \text { Symptoms score ranged from } 5 \text { (very great deal of discomfort or distress) to } 35 \text { (no discomfort or distress); see } \\
\text { Methods. } \\
\text { FEV } 1 \text { predicted values from Crapo et af }{ }^{8} \text { and are pre-bronchodilator. } \\
{ }^{* *} \text { Geometric mean (geometric SD). }\end{array}$} \\
\hline
\end{tabular}

over 8 weeks which was initiated, planned, performed, analysed and reported without influence from industry. The primary outcome was the effect of treatment on sputum eosinophils. Secondary outcomes were improvement in clinical variables (symptoms, bronchodilator use and prebronchodilator $\mathrm{FEV}_{1}$ ).

There were six visits to the clinic, each at the same time of day \pm 2 hours. At the initial visit inclusion and exclusion criteria were reviewed, pre and post salbutamol spirometric tests and sputum induction were performed, and peripheral blood was collected for liver function tests. Subjects who met the entry criteria returned on the following day for visit 2 when clinical characteristics were recorded, allergy skin prick tests and, if necessary a methacholine inhalation test was performed. Subjects were also instructed on how to complete a diary card of symptoms, peak expiratory flow (PEF) for safety, medication use, and adverse events. They were then randomly allocated to receive daily fluticasone $50 \mu \mathrm{g}$ two puffs in the morning and three puffs in the evening $(250 \mu \mathrm{g} /$ day) and placebo tablet in the evening, montelukast $10 \mathrm{mg}$ in the evening and placebo inhaler, or placebo inhaler and placebo tablet. Subsequent visits were on days 7, 14, 28 and 56 (visits 3, 4, 5 and 6). The procedures at these included symptom questionnaires and adverse events, review of diary cards, spirometry, induced sputum, and a compliance check. Blood for liver function tests was also taken at day 56.

Exacerbations were defined by a worsening of symptoms requiring treatment with four or more extra puffs/day of short acting $\beta_{2}$ agonist from baseline over 48 hours, or by nocturnal or early morning waking two or more times over baseline, or by a fall in pre-bronchodilator $\mathrm{FEV}_{1}$ of $\geqslant 15 \%$ from initial spirometry. If an exacerbation occurred, fluticasone $125 \mu \mathrm{g}$ two puffs twice daily was added to the treatment; if patients continued to exacerbate they were withdrawn from the trial and treated appropriately.

\section{Measurements}

Questionnaires were used to document subject characteristics. Symptom severity (chest tightness, shortness of breath, wheezing, cough and nocturnal and/or early morning awakening) was graded on a validated 7 point Likert scale. ${ }^{28}$ Symptom scores ranged from 5 (most severe discomfort) to 35 (asymptomatic). Daily use of short acting $\beta_{2}$ agonist was also recorded. Allergy skin prick tests, spirometric tests, and methacholine inhalation tests were carried out by standardised methods. ${ }^{29-32}$ Compliance with medications was checked by weighing inhaler canisters and counting tablets. PEF measurements were performed with a mini-Wright peak flow meter on waking and before bed. Sputum induction ${ }^{33}$ and processing ${ }^{6}$ for total and differential cell counts were performed by the methods described by Pizzichini et al. Liver function tests (bilirubin, alanine transaminase, aspartate transaminase, gamma glutamyl transaminase, and alkaline phosphatase) were performed by routine laboratory methods.

\section{Sample size}

Sample size estimation was calculated for the study primary outcome measure-the difference in sputum eosinophil count between fluticasone and montelukast. In a previous study $^{34}$ comparing beclomethasone (BDP) with placebo in mildly uncontrolled asthma, BDP $1000 \mu \mathrm{g}$ daily reduced the baseline sputum eosinophil count from a mean (SD) of $22.5(17.9) \%$ to $5.7(6.8) \%$. Montelukast has been shown to reduce the sputum eosinophil count in mild asthmatics from $7.5 \%$ to $3.9 \%$ (95\% CI -16.6 to 0.4$).{ }^{18}$ Based on these data, a sample size of 16 in each active arm would have $80 \%$ power to detect an absolute difference of $13 \%$ in the reduction in the eosinophil count by fluticasone compared with montelukast at an alpha of 0.05 (two tailed) and a beta of 0.2.

\section{Statistical analysis}

Descriptive statistics were used to summarise the clinical characteristics of the participants. Variables with non-normal distribution (sputum total cell count and eosinophils) were $\log$ transformed before analysis. ANOVA with post hoc analysis adjusted for multiple comparisons were used to determine the comparability between groups at baseline. The effects of treatment on the primary and secondary outcomes were compared using a two factor repeated measures ANOVA adjusting for baseline differences. The within subject factor was repeated measures (or time) before and after treatment. The between subject factors were centre and treatment group. Change and percentage change from baseline were examined for each outcome. Significant variation between groups was identified by the Tukey test and the p value was adjusted for multiple comparisons. All statistical tests were two sided and significance was accepted at the $95 \%$ level. The end point was defined as the last value obtained before any added open label fluticasone. The least clinically important difference in sputum eosinophils after intervention was regarded as a $50 \%$ reduction ${ }^{35}$ and for $\mathrm{FEV}_{1}$ was a change of $>12 \%$.

\section{RESULTS}

\section{Randomisation, withdrawals, exacerbations and compliance}

Fifty eligible participants were randomised to the treatment groups: 19 to receive montelukast, 18 to receive fluticasone 


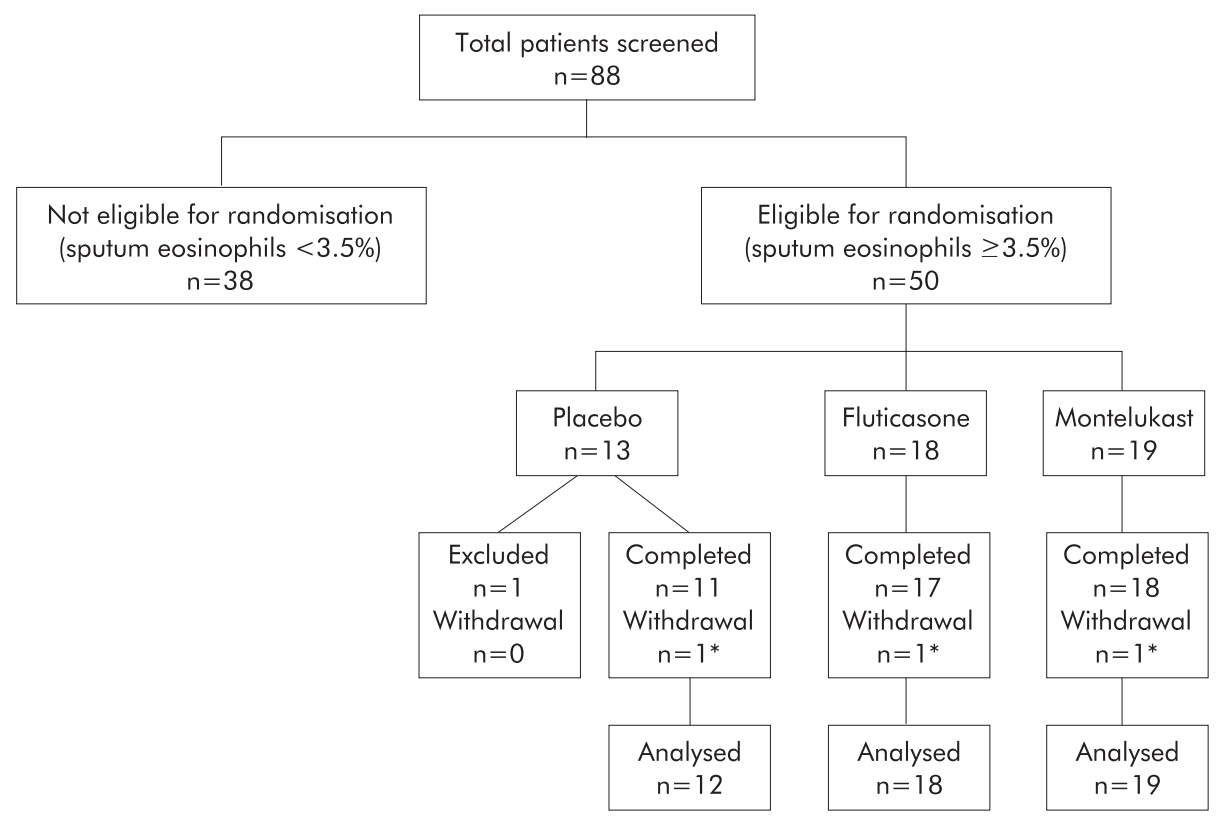

Figure 1 Profile of trial.

and 13 to receive placebo (fig 1). There were no significant differences in clinical or physiological parameters between the treatment groups at baseline (table 1). One patient in the placebo group was excluded from the study early after randomisation because of protocol violation and was not included in the analysis. Of the remaining 49 patients, one in each group was withdrawn before the end of the study: one on montelukast after 2 weeks and one on placebo after 4 weeks were lost to follow up, and one on fluticasone after 2 weeks had a rash, abdominal discomfort and dysuria. All the available results for these patients before withdrawal were analysed. Four patients exacerbated during the study, requiring open label fluticasone: one on placebo, two on montelukast, and one on fluticasone. One subject exacerbated at day 7 (placebo) and three at day 14; their results were analysed up to these visits. They then received open labelled fluticasone and were improved by the added treatment. Compliance was satisfactory $(>96 \%)$.

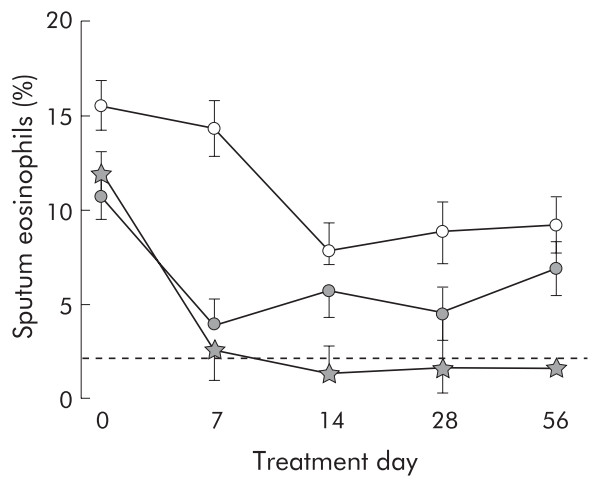

Figure 2 Effects of treatment on sputum eosinophils expressed as geometric mean and error. Fluticasone (stars) completely suppressed sputum eosinophilia after 4 and 8 weeks of treatment ( $\mathrm{p}$ at 8 weeks = 0.04 and 0.002 , respectively, $v$ placebo (open circles) and montelukast (closed circles)). Treatment with montelukast attenuated sputum eosinophilia only up to 4 weeks ( $p=0.9$ after 8 weeks).

\section{Effects on sputum eosinophilia}

The percentage of eosinophils did not differ significantly between the three groups at the pretreatment visit (table 1). After fluticasone treatment an important decrease in sputum eosinophilia was measured as early as 7 days from a geometric mean (SD) of $11.9(2.3) \%$ to 2.5 (5.1)\% (fig 2). After 4 and 8 weeks fluticasone completely suppressed sputum eosinophilia to $1.7(4.5) \%$ and $1.7(5.1) \%$ (table 2 , fig 2). Treatment with montelukast only attenuated sputum eosinophilia up to 4 weeks. After 7 days, 4 weeks and 8 weeks montelukast reduced sputum eosinophilia from $10.7(2.3) \%$ to $3.8(3.8) \%, 4.5 \quad(3.5) \%$ and $6.9(3.8) \%$ $(\mathrm{p}=0.9$ in comparison with placebo at the end of the study). Placebo treatment did not significantly affect sputum eosinophils after 7 days, 4 weeks or 8 weeks. The geometric mean difference between the effects of fluticasone and placebo on sputum eosinophils was $-4.0 \%$ (95\% CI -10.2 to -1.6$), \mathrm{p}=0.002$ and montelukast was $-2.3 \% \quad(95 \% \mathrm{CI}$ -5.2 to -1.0$), \mathrm{p}=0.04$.

We also examined the effects of the study treatments on sputum eosinophilia as a percentage reduction. The median reduction in sputum eosinophilia after fluticasone on day 7 was $72.7 \%$ compared with $56.2 \%$ and $34.9 \%$ after montelukast and placebo. At 8 weeks the eosinophilia, in comparison with baseline, was reduced by $84.1 \%$ after fluticasone, $17.5 \%$ after montelukast, and $31.4 \%$ after placebo.

\section{Effects on clinical variables}

The effects of treatment on clinical variables are shown in table 2. Treatment with fluticasone produced a significant increase in pre-bronchodilator $\mathrm{FEV}_{1}$ by day 7 (fig 3) which was maintained (fig 4). The mean change in $\mathrm{FEV}_{1}$ on day 7 was $425 \mathrm{ml} \mathrm{(95 \%} \mathrm{CI} 151.7$ to 698.3 ) after fluticasone, $33 \mathrm{ml}$ (95\% CI -108 to 174$)$ after montelukast, and $-142 \mathrm{ml}(95 \%$ CI -355 to 70 ) after placebo. By 8 weeks the $\mathrm{FEV}_{1}$ was increased by $475 \mathrm{ml}$ (95\% CI 131 to 820 ) after fluticasone, $156 \mathrm{ml}$ (95\% CI -77.7 to 383 ) after montelukast, and $125 \mathrm{ml}$ (95\% CI -64 to 250 ) after placebo. The difference between the effects of fluticasone and placebo on $\mathrm{FEV}_{1}$ was $458 \mathrm{ml}$ (95\% CI 73 to 842 ) and between fluticasone and montelukast was $373 \mathrm{ml}$ (95\% CI 26 to 720$) ; \mathrm{p}=0.02$ and 0.03 for both comparisons. 
Table 2 Primary and secondary outcomes at baseline and 8 weeks after treatment

\begin{tabular}{|c|c|c|c|c|c|c|}
\hline & \multicolumn{2}{|l|}{ Placebo } & \multicolumn{2}{|l|}{ Fluticasone } & \multicolumn{2}{|c|}{ Montelukast } \\
\hline & Day 0 & Day 56 & Day 0 & Day 56 & Day 0 & Day 56 \\
\hline \multicolumn{7}{|l|}{ Induced sputum } \\
\hline Total cell count $\left(\times 10^{6} / \mathrm{g}\right)$ & $2.0(2.6)$ & $2.5(2.3)$ & $3.9(2.1)$ & $4.9(1.8)$ & $3.1(2.3)$ & $4.6(2.3)$ \\
\hline Eosinophils (\%) & $15.4(2.4)$ & $7.8(4.2)$ & $11.9(2.3)$ & $1.7(5.1)^{*}$ & $10.7(2.3)$ & $6.9(3.8)$ \\
\hline Neutrophils (\%) & $27.4(20)$ & $28.7(23)$ & $28.9(21)$ & $35.3(28)$ & $24.2(15)$ & $36.0(27)$ \\
\hline \multicolumn{7}{|l|}{ Clinical parameters } \\
\hline Symptoms score & $22.5(4.5)$ & $28.3(5.1)$ & $23.2(6.4)$ & $30.5(4.3)$ & $25.6(5.5)$ & $28.5(5.9)$ \\
\hline Salbutamol (puffs/day) & $2.7(1.9)$ & $2.1(1.5)$ & $3.3(2.6)$ & $0.8(0.9)$ & $3.3(3.1)$ & $2.5(2.7)$ \\
\hline $\mathrm{FEV}_{1}(\mathrm{l}) \dagger$ & $2.4(0.8)$ & $2.4(0.9)$ & $2.6(0.9)$ & $3.0(0.9) \ddagger$ & $2.8(0.7)$ & $2.8(0.9)$ \\
\hline
\end{tabular}

Induced sputum data are expressed as geometric mean (SD) except neutrophils which are expressed as mean (SD). Clinical parameters data are expressed as mean (SD).

Symptoms score as in table 1.

* $p$ values adjusted for baseline values for comparisons between treatment arms: fluticasone $v$ placebo, $p=0.004 ;$ fluticasone $v$ montelukast, $p=0.008$; montelukast $\checkmark$ placebo, $p=0.9$.

tPre-bronchodilator values.

的 values adjusted for baseline values for comparisons between treatment arms: fluticasone $v$ placebo, $p=0.02$; fluticasone $v$ montelukast, $p=0.01$; montelukast $v$ placebo, $p=0.9$.

\section{Side effects}

One subject who was previously well apart from asthma, and who had no alcohol intake and normal baseline serum liver function tests, developed evidence of a drug induced hepatitis after 2 months of treatment with montelukast. The bilirubin and aspartate transaminase, which were previously normal, rose to $30 \mathrm{mmol} / \mathrm{l}$ and $62 \mathrm{U} / \mathrm{l}$, respectively, at the final visit and fell to normal levels 3 weeks after the drug was discontinued.

\section{DISCUSSION}

In this study we have examined repeatedly at different time points the anti-inflammatory effects of fluticasone and montelukast on the airway eosinophilic inflammation of subjects with steroid naive asthma. The results show that treatment with fluticasone suppresses sputum eosinophils and significantly improves $\mathrm{FEV}_{1}$. These effects of fluticasone were observed by 7 days and were maintained during the 8 weeks of the study. Treatment with montelukast attenuated and had its greatest effect on airway eosinophilia by day 7. However, in contrast to fluticasone, the effect only lasted 4 weeks. In addition, montelukast had no effect on $\mathrm{FEV}_{1}$. Placebo treatment did not affect sputum eosinophilia or improve $\mathrm{FEV}_{1}$. These results are relevant to the treatment of asthma with sputum eosinophilia in patients who are not
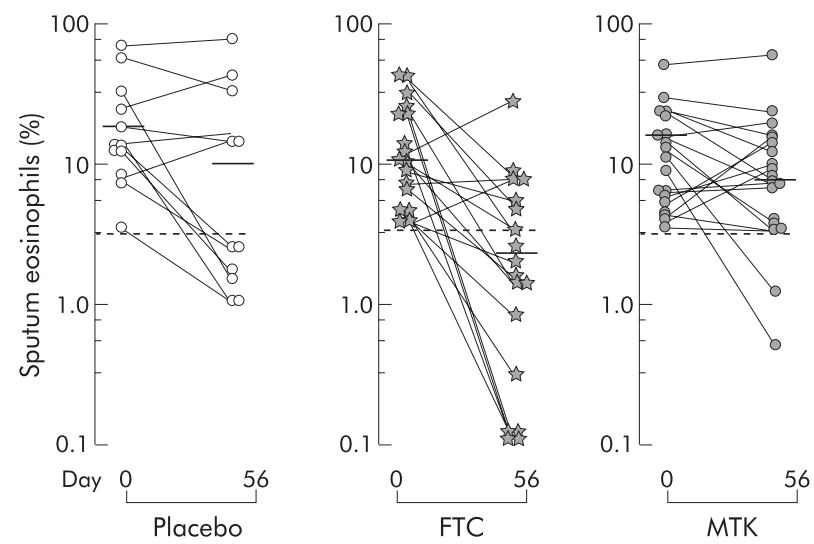

Figure 3 Individual plots of percentage sputum eosinophils at day 0 and at the end of the treatment period (day 56) with placebo, fluticasone (FTC) and montelukast (MTK). At the end of the study fluticasone treatment significantly reduced sputum eosinophils while treatment with placebo or montelukast did not. receiving inhaled steroids, but not to similar patients without sputum eosinophilia.

This is the first study to compare repeatedly at several time points the anti-inflammatory effects of a low dose of fluticasone with montelukast in symptomatic steroid naive asthmatics with airway eosinophilia in a placebo controlled study. The results are consistent with other published observations that have shown that leukotriene modifiers, including montelukast, reduce eosinophilic airway inflammation $^{1819}$ and that inhaled steroids, including fluticasone, suppress it. ${ }^{34} 3637$ The failure of fluticasone to completely suppress sputum eosinophilia during the 8 weeks of the study in six of 18 subjects indicates that some patients may require a higher steroid dose. The novel and unexpected finding was a non-sustained anti-inflammatory effect of montelukast at 8 weeks. This is intriguing and questions the use of montelukast as an alternative anti-inflammatory treatment to inhaled steroid in mild persistent asthma, as suggested by one asthma guideline. ${ }^{2}$ The inability of montelukast to maintain a clinically important attenuation of airway eosinophilia at 8 weeks of treatment in the present study does not seem to be due to compliance, nor does it seem to be due to a placebo response or to sample size since this was based on the results of an earlier study when montelukast had a sputum eosinophil lowering effect. ${ }^{18}$ The explanation is uncertain. The possibilities are that the antiinflammatory effect is too selective or weak or that the dose

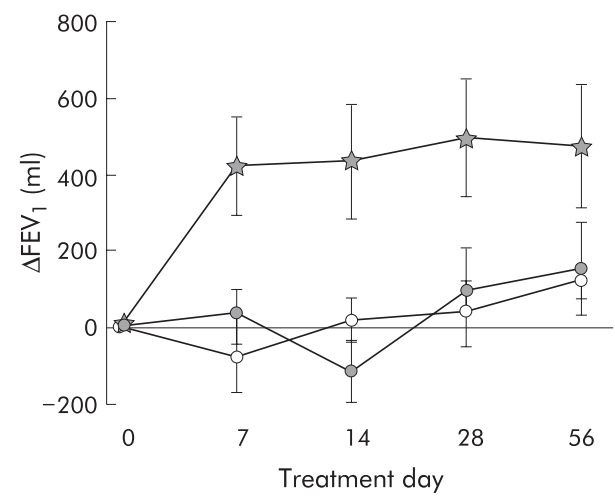

Figure 4 Effects of treatment with fluticasone (stars), montelukast (closed circles), and placebo (open circles) on pre-bronchodilator $\mathrm{FEV}_{1}$. Fluticasone treatment produced a significant increase in $\mathrm{FEV}_{1}$ as early as day 7 which was maintained throughout the study. Montelukast treatment had no effect on $\mathrm{FEV}_{1}$. 
used, although regarded to give maximal effects, is not enough to prevent further increases in airway eosinophilia due to various stimuli.

This study is also the first to show that low dose fluticasone is more effective than montelukast for controlling sputum eosinophilia in steroid naive asthma. The only other study to compare the effects did not select subjects with sputum eosinophilia or include a placebo control. ${ }^{27}$ It failed to show a difference in the effects of fluticasone and montelukast on sputum eosinophils and failed to show an anti-inflammatory effect of montelukast on eosinophils after 4 weeks of treatment. Possible explanations for the different results in the latter study include the lack of selection of asthmatics with airway eosinophilia so that there was not enough signal to demonstrate an anti-inflammatory effect, ${ }^{34}$ or the variable washout period of 3-6 weeks between treatment phases of a crossover design.

The design of the present study has several strengths. One of these is the placebo arm which excludes the regression to the mean as the cause of changes in airway inflammation. ${ }^{38}$ Another strength is the selection of a homogenous population of patients with eosinophilic inflammation to enable a clear signal of anti-inflammatory effects of the drugs to be shown on sputum eosinophils. However, by selecting our patients we decreased the generalisability of the results to patients with symptomatic asthma who have no eosinophilia. The prevalence of symptomatic non-eosinophilic asthma (sputum eosinophils $<2 \%$ ) in a large population of steroid naive asthma is uncertain. It has been reported to occur in approximately $35-40 \%$ of the patients presenting in tertiary clinics. $^{39}{ }^{40}$ On the other hand, the lack of selection of homogenous groups of subjects with asthma may help to explain the lack of the steroid response in clinical trials which has been reported to be as high as $40 \%{ }^{41}$

While there has been some recent controversy on the role of eosinophils in the pathogenesis of asthma, ${ }^{42}{ }^{43}$ sputum eosinophilia is an important clinical marker of response to steroid treatment ${ }^{44}{ }^{45}$ and the present results support this. The importance of suppressing airway eosinophilia has been further confirmed by two longitudinal studies which compared the monitoring of asthma treatment using sputum eosinophils with symptoms and $\mathrm{FEV}_{1}{ }^{46}{ }^{47}$ Both studies showed that the use of sputum cell counts decreased the exacerbation rates by at least $50 \%$ without the need for an increase in inhaled steroid treatment.

The present study also showed an improvement in clinical indices of asthma with fluticasone, as indicated by improvement in symptoms, rescue salbutamol, and $\mathrm{FEV}_{1}$. The same was not observed in the group of subjects on montelukast. Although these results differ from previous publications which show that montelukast has bronchodilator ${ }^{48}$ and bronchoprotective ${ }^{49}$ properties and, despite the sample size, had not been estimated for this outcome, the present results are in keeping with our previous publication. ${ }^{18}$ The greater improvement in $\mathrm{FEV}_{1}$ caused by inhaled steroid over antileukotriene receptor antagonists has been seen in other studies. ${ }^{25} 2631$ In one of these, Busse et $a l^{25}$ found that the addition of low dose fluticasone $88 \mu \mathrm{g}$ twice daily for 24 weeks to albuterol alone in 533 symptomatic patients improved $\mathrm{FEV}_{1}$, morning and evening PEF, symptom free days, and albuterol use more than montelukast. However, montelukast is an active drug and seems to be effective in some patients. The challenge is to identify how to predict which patients will receive treatment benefit.

We conclude that fluticasone treatment is more effective than montelukast in symptomatic steroid naive adults with asthma who have sputum eosinophilia and who would be expected to improve with steroid treatment. This should question the advisability of using montelukast as first line treatment in these patients. However, the effect of montelukast in symptomatic steroid non-eosinophilic asthma was not studied and still requires investigation.

\section{ACKNOWLEDGEMENTS}

The authors thank the subjects who participated in the study; A Efthimiadis, S Carruthers, S Weston, M Prodaniuk and S Ferreira for performing the sputum cell counts; and P Hussack, S Goodwin, S Chaboillez, M Langevin and Julie Cristina Nunes for performing the clinical procedures.

\section{Authors' affiliations}

L Jayaram, F E Hargreave, Airways Research Group, Firestone Institute for Respiratory Health, St Joseph's Healthcare and McMaster University, Hamilton, Ontario

E Pizzichini, M M M Pizzichini, NUPAIVA, Universidade Federal de Santa Catarina, Florianopolis, Brazil

C Lemière, A Cartier, Hôpital du Sacré-Coeur de Montréal, Montréal, Québec

S F P Man, University of Alberta, Edmonton, Alberta

This study was partially supported by a medical school grant from Glaxo Wellcome Inc; L Jayaram was supported by a Fellowship from Boehringer Ingelheim (Canada) Inc; F E Hargreave is supported by the Father Sean O'Sullivan Research Centre.

\section{REFERENCES}

1 Boulet LP, Becker A, Berube D, et al. Canadian asthma consensus report 1999. Canadian Asthma Consensus Group. Can Med Assoc J 1999:161/11 Suppl):S1-61

2 National Asthma Education and Prevention Program Expert Panel. Report 2: Guidelines for the diagnosis and management of asthma. Publication No 97. Bethesda, MD: National Institutes of Health, National Heart Lung, and Blood Institute, 2002:1-50

3 Bousquet J, Chanez P, Lacoste JY. Asthma: a disease remodeling the airways. Allergy 1992;47:3-11

4 Homer RJ, Elias JA. Consequences of long-term inflammation. Airway remodelling. Clin Chest Med 2000;21:331-43.

5 Belda J, Leigh R, Parameswaran K, et al. Induced sputum cell counts in healthy adults. Am J Respir Crit Care Med 2000;161:475-8.

6 Pizzichini E, Pizzichini MMM, Efthimiadis A, et al. Indices of airway inflammation in induced sputum: reproducibility and validity of cell and fluid phase measurements. Am J Respir Crit Care Med 1996;154:308-17.

7 Jayaram L, Parameswaram K, Sears MR, et al. Induced sputum cell counts: their usefulness in clinical practice. Eur Respir J 2000;16:150-8.

8 Pizzichini MM. Is sputum eosinophilia a good or poor predictor of benefit from inhaled corticosteroid therapy in asthma? Eur Respir J 2002;20:1359-61

9 Haahtela T, Jarnivean $M$, Kava T. Comparison of a $\beta_{2}$-agonist, terbutaline, with an inhaled corticosteroid, budesonide, in newly detected asthma. N Engl J Med 1991;325:388-92.

10 Pedersen S, Hansen OR. Budesonide treatment of moderate and severe asthma in children: a dose-response study. J Allergy Clin Immunol 1995;95:29-33.

11 Busse WW, Chervinsky P, Condemi J, et al. Budesonide delivered by Turbuhaler is effective in a dose-dependent fashion when used in the treatment of adult patients with chronic asthma. J Allergy Clin Immunol 1998;101:457-63.

12 Juniper EF, Kline PA, Vanzieleghem MA, et al. Effect of long-term treatment with an inhaled corticosteroid (budesonide) on airway hyperresponsiveness and clinical asthma in nonsteroid-dependent asthmatics. Am Rev Respir Dis 1990;142:832-6

13 Dutoit JI, Salome CM, Woolcock AJ. Inhaled corticosteroids reduce the severity of bronchial hyperresponsiveness in asthma but oral theophylline does not. Am Rev Respir Dis 1987;136:1174-8.

14 Pauwels RA, Lofdahl CG, Postma DS, et al. Effect of inhaled formoterol and budesonide on exacerbations of asthma. N Engl J Med 1997;337:1405-11.

15 Haahtela T, Klaukka T. Societal and health care benefits of early use of inhaled steroids. Thorax 1998;53:1005-6.

16 Suissa S, Ernst P, Kezouh A. Regular use of inhaled corticosteroids and the long-term prevention of hospitalization for asthma. Thorax 2002;57:880-4

17 Suissa S, Ernest P, Benayoun S, et al. Low-dose inhaled corticosteroids and the prevention of death from asthma. N Engl J Med 2000;343:332-6.

18 Pizzichini E, Leff JA, Reiss TF, et al. Montelukast reduces airway eosinophilic inflammation in asthma: a randomized, controlled trial. Eur Respir J 1999;14:12-8

19 Minogushi K, Kohno Y, Minogushi H, et al. Reduction of eosinophilic inflammation in the airways of patients with asthma using montelukast. Chest 2002; 121:732-8

20 Leigh R, Vethanayagam D, Yoshida $M$, et al. Effects of montelukast and budesonide on airway responses and airway inflammation in asthma. Am J Respir Crit Care Med 2002; 166:1212-7.

21 Reiss TF, Chervinsky P, Dockhorn RJ, et al. Montelukast, a once-daily leukotriene receptor antagonist, in the treatment of chronic asthma. A 
multicenter, randomized, double-blind trial. Arch Intern Med 1998; 158:1213-20

22 Reiss TF, Sorkness CA, Stricker W, et al. Effect of montelukast (MK-0476); a potent cysteinyl leukotrine receptor antagonist, on bronchodilatation in asthmatic subjects treated with and without inhaled corticosteroids. Thorax 1997;52:45-8.

23 Bisgaard H, for the Study Group on Montelukast and Respiratory Syncytial Virus. A randomized trial of montelukast in respiratory syncytial virus postbronchiolitis. Am J Respir Crit Care Med 2003;167:379-83.

24 Barnes NC, Miller CJ. Effect of leukotrine receptor antagonist therapy receptor antagonist therapy on the risk of asthma exacerbation in patients with mild to moderate asthma: an integrated analysis of zafirlukast trials. Thorax 2000:55:478-83.

25 Busse W, Raphael GD, Galant S, for the Fluticasone Proprionate Clinical Research Study Group, et al. Low-dose fluticasone propionate compared with montelukast for first-line treatment of persistent asthma: a randomized clinical trial. J Allergy Clin Immunol 2001;107:461-8.

26 Bleecker ER, Welch MJ, Weinstein SF, et al. Low-dose inhaled fluticasone proprionate versus oral zafirlukast in the treatment of persistent asthma. $J$ Allergy Clin Immunol 2000;105:1223-9.

27 Bleecker ER, Welch MJ, Weinstein SF, et al. Low-dose inhaled fluticasone proprionate versus oral zafirlukast in the treatment of persistent asthma. $J$ Allergy Clin Immunol 2000; 105: 1223-9.

28 Gibson PG, Wong BJO, Hepperle MJE, et al. A research method to induce and examine a mild exacerbation of asthma by withdrawal of inhaled corticosteroid. Clin Exp Allergy 1992;22:525-32.

29 Pepys J. Skin test in diagnosis. In: Gell PGH, Coombs RRA, Lachmann PJ, eds. Clinical aspects of immunology.3rd ed. Oxford: Blackwell Scientific Publications, 1975:55-80.

30 American Thoracic Society. Standardization of spirometry. 1994 update. Am Rev Respir Dis 1995;152:1107-36.

31 Crapo RO, Morris AH, Gardner RM. Reference spirometric values using techniques and equipment that meets ATS recommendation. Am Rev Respir Dis 1981;123:659-94.

32 Juniper EF, Cockroft DW, Hargreave FE. Histamine and methacholine inhalation test: a laboratory tidal breathing protocol. Lund, Sweden: Astra Draco AB, 1994.

33 Pizzichini MMM, Popov T, Pizzichini E, et al. Spontaneous and induced sputum compared. Am J Respir Crit Care Med 1996;154:866-9.

34 Turner MO, Johnston PR, Pizzichini E, et al. Anti-inflammatory effects of salmeterol compared with beclomethasone in eosinophilic mild exacerbations of asthma: a randomized, placebo controlled trial. Can Respir J 1998;5:261-8
35 Kips J, Inman MD, Jayaram $L$, et al. The use of induced sputum in clinical trials. Eur Respir J Suppl 2002;37:47-50s.

36 Pavord ID, Brightling CE, Wolkman G, et al. Non-eosinophilic corticosteroid unresponsive asthma. Lancet 1999;353:2213-4.

37 van Resen EL, Straathof KCM, Maud AVC, et al. Effect of inhaled steroids on airway hyperresponsiveness, sputum eosinophils, and exhaled nitric oxide levels in patients with asthma. Thorax 1999;54:403-8.

38 Yudkin PL, Stratton IM. How to deal with regression to the mean intervention studies. Lancet 1996;347:241-3.

39 Louis R, Sele J, Henket $M$, et al. Sputum eosinophil count in a large population of patients with mild to moderate steroid-naïve asthma: distribution and relationship with methacholine bronchial hyperresponsiveness. Allergy 2002;57:907-12.

40 Lee SVS, Pizzichini MMP, Marques $\sqcup$, et al. Inflamacao das vias aereas em asmaticos virgens de tratamento com esteroides: caracteristicas do escarro induzido. J Pneumol 2003;29:188-95.

41 Malmstrom K, Rodriguez-Gomez G, Guerra J, for the Montelukast/ Beclomethasone Study Group, et al. Oral montelukast, inhaled beclomethasone, and placebo for chronic asthma. A randomized control trial. Ann Intern Med 1999; 16:487-95.

42 Leckie MJ, ten Brinke A, Khan J, et al. Effects of an interleukin-5 blocking monoclonal antibody on eosinophils, airway hyperresponsiveness, and the late asthmatic response. Lancet 2000;356:2144-8.

43 O'Byrne PM, Inman MD, Parameswaran K. The trials and tribulations of IL-5, eosinophils, and allergic asthma. J Allergy Clin Immunol 2001;108:503-8.

44 Green RH, Brightling CE, Woltmann G, et al. Analysis of induced sputum in adults with asthma: identification of subgroup with isolated sputum neutrophilia and poor response to inhaled corticosteroids. Thorax 2002;57:875-9.

45 Pizzichini E, Pizzichini MM, Gibson P, et al. Sputum eosinophilia predicts benefit from prednisone in smokers with chronic obstructive bronchitis. Am J Respir Crit Care Med, 1998;158:1511-7.

46 Green RH, Brightling CE, McKenna S, et al. Asthma exacerbations and sputum eosinophil counts: a randomised controlled trial. Lancet 2002;360:1715-21

47 Jayaram L, Hussack H, Boulet LP, et al. The LOMA study: effect on asthma exacerbations in the first year. Am J Respir Crit Care Med 2003;167:A976.

48 Reiss TF, Sorkness CA, Stricker W, et al. Effect of montelukast (MK-0476); a potent cysteinyl leukotrine receptor antagonist, on bronchodilatation in asthmatic subjects treated with and without inhaled corticosteroids. Thorax 1997;52:45-8.

49 Leff JA, Busse WW, Pearlman D, et al. Montelukast, a leukotrine receptor antagonist, for the treatment of mild asthma and exercise induced bronchoconstriction. N Engl J Med 1998;339:147-52.

\section{EDITORIAL NOTICE}

In the May 2003 issue of Thorax we published a paper by Brusasco and colleagues on the subject of health outcomes following treatment with tiotropium.' This paper reported the results of two 6 month studies that were combined for the purpose of analysis in this paper. One of these studies had been previously published by Donohue et al in Chest and not referenced by Brusasco and colleagues. ${ }^{2}$ Thorax wishes to bring the overlap between these two papers to the attention of readers.

1 Brusasco V, Hodder R, Miravitlles M, Korducli L, Towse L, Kesten S. Health outcomes following treatment with tiotropium compared with twice daily salmeterol in patients with COPD. Thorax 2003;58:399-401

2 Donohue JF, van Noord JA, Bateman ED, Langley SJ, Lee A, Witek TJ, Kesten S, Towse L. A 6-month, placebo- controlled study comparing lung function and health status changes in COPD patients treated with tiotropium or salmeterol. Chest 2002;122:47-55. 